\title{
CADALSO LEYÉNDOSE A SÍ MISMO NOTAS PARA UNA EDICIÓN
}

\author{
Miguel Ángel Lama
}

\begin{abstract}
Among the manuscripts of José de Cadalso (1741-1782) published in the late nineteenth century by the French hispanist R. Foulché-Delbosc, there was evidence that the writer from Cádiz had a special concern for revising his poetry published in the book entitled Ocios de mi juventud, in 1773. This article points out that those annotations by the poet must be taken into consideration - for the first time - for a future edition of the poetry of Cadalso.

Keywords: José de Cadalso; poetry; Ocios de mi juventud; Eighteenth Century; textual transmission.

Resumen: Entre los manuscritos de José de Cadalso (1741-1782) difundidos a finales del siglo XIX por el hispanista francés R. Foulché-Delbosc había pruebas de la preocupación del escritor gaditano por la revisión de su obra poética publicada en el volumen Ocios de mi juventud, de 1773. La propuesta de este artículo es que aquellas apuntaciones del poeta sean tenidas en cuenta -lo serían por primera vez- en una futura edición de la poesía de Cadalso.
\end{abstract}

Palabras claves: José de Cadalso; poesía; Ocios de mi juventud; Siglo XVIII; transmisión textual.

Los poemas que José de Cadalso (1741-1782) publicó en vida se reunieron en el libro titulado Ocios de mi juventud, salido de la imprenta de Antonio de Sancha en 1773 y firmado bajo el seudónimo de Josef Vázquez (Cadalso 1773). Era una identidad compuesta por su nombre de pila y el segundo de sus apellidos y que coincidía con el nombre y apellido de su abuelo materno. Bajo este disfraz apareció casi todo lo que publicó el escritor gaditano antes de su muerte, que fue poco: Los eruditos a la violeta y el Suplemento a los Eruditos a la violeta en 1772, y los citados Ocios al año siguiente. Con otro nombre falso, el de Juan del Valle, se había publicado su primer texto, su tragedia Sancho García (Cadalso 1771). No hubo más. De hecho, lo más conocido de la producción literaria de Cadalso se publicó póstumamente y fue lo que le dio fama: las Cartas marruecas y las Noches lúgubres ${ }^{1}$. Precisamente, como recordó Emilio Martínez Mata (2000: LXVI), «buena parte de los problemas textuales que ofrecen las obras de Cadalso se debe a que muchas de ellas, entre las que hay que contar las Cartas marruecas y las Noches lúgubres, no pudieron ser publicadas por su autor». La transmisión textual de ambas obras está marcada por la ausencia de

\footnotetext{
1 Tanto las Cartas marruecas como las Noches lúgubres se publicaron por primera vez en el Correo de Madrid. Las primeras, en 1789 (números 233 a 280); las segundas, entre diciembre de 1789 y enero de 1790 (números 319, $322,323$ y 325$)$.
}

Romanica Olomucensia 24.2 (2012): 159-168 
testimonios de relación directa del autor con el proceso de creación, tales como manuscritos autógrafos, de los que carecemos en lo que se refiere a estas dos piezas en prosa, u otro tipo de pruebas fehacientes de corrección o reescritura. Esto es aplicable a casi toda su producción.

En el caso de la poesía lírica es más clara -aparentemente- esa relación ya que contamos con tres ediciones casi idénticas $(1773,1781,1782)$ de los Ocios de mi juventud publicadas en vida del escritor. El resto de su poesía apareció póstumamente ${ }^{2}$. Así se ha venido editando la poesía de Cadalso desde principios del siglo XIX, desde la edición de sus Obras (Cadalso 1803), en cuyo volumen tercero se recogieron las composiciones poéticas. Por un lado, los Ocios, por otro los primeros poemas inéditos que se publicaron tras la muerte del escritor, bajo el título de Epístola dedicada a Hortelio, o Poesías inéditas (Cadalso 1792), más nuevos poemas desconocidos que se incorporaron a ediciones posteriores ${ }^{3}$. He dicho aparentemente porque no es tan simple la historia textual de la poesía cadalsiana. El autor de las Cartas marruecas no debió tener ninguna responsabilidad en las reimpresiones -las de 1781 y 1782- que de sus poemas se publicaron antes de su muerte, aunque las hubiese conocido; y no tuvo esa responsabilidad porque esas reediciones no contemplaron las instrucciones que él dejó escritas por si se volvía a publicar su poesía.

La confirmación de que Cadalso se preocupó, después de la publicación de sus Ocios en 1773, de que su obra poética debía publicarse o volverse a editar correctamente, está en su correspondencia. De la primavera de 1775 es una carta dirigida a Meléndez Valdés desde Montijo en la que Cadalso (1979: 102-104) alude a sus papeles:

Mi querido sobrino:

En cumplir a Vmd. la palabra que le he dado de dejarle por depositario de mis manuscritos mientras voy a la guerra, y por heredero de ellos si no vuelvo, logro, o pretendo lograr dos gustos. El $1^{\circ}$ es dar a Vmd. y al público una prueba evidente del afecto que le cobré durante mi mansión en Salamanca. El $2^{\circ}$ es, que en caso de morir en campaña, no se me atribuyan obras algunas póstumas que yo no haya hecho. Ni quiero que se note mi memoria con los papeles que se den a luz en mi nombre si son malos ni que se me honre con los que no merezco si son buenos. [...]

Algunas otras he escrito a personas altas y bajas que tal vez importan algo: singularmente una larga correspondencia, que mantuve durante mi destierro en Aragón, con un amigo cuyo mérito y prendas he celebrado en mis débiles poesías bajo el nombre de Ortelio; y con la marquesa de E [scalona], pero a mi regreso a Madrid quemé cartas y respuestas.

Otra tuve igual, a saber: mi colección de cartas y respuestas a Don Joaquín Oquendo, cuyo nombre ocupa una página muy larga y curiosa en el Compendio de mi vida; y finalmente hay otra serie de cartas y borradores de respuestas mías a una dama joven y llena de talento, que me ha escrito a Montijo, filosofando mejor que muchos hombres que conozco preciados de filosofar. La incluyo entre los papeles que dejo a Vmd porque quiero yo que, muerto yo, nadie la vea primero que $\mathrm{Vmd}$, a quien encargo no las publique con el nombre de la señora. Mi correspondencia con el Literato Napolitano es muy corta, pero capaz de envanecerme, si yo apreciase en algo las cosas de este mundo. Incluyo también un juego de los Eruditos, Suplemento y Poesías con las correcciones necesarias para otra impresión, que intento hacer si vivo, o para cualquiera que se haga si muero. [...]

\footnotetext{
2 La edición publicada en Barcelona (Cadalso 1782) llevaba un colofón de 21 de diciembre de 1781; pero es improbable que el autor, como ha señalado Manuel Camarero (1987: 104, n. 48), la viese.

3 Sobre la fortuna póstuma de la poesía de Cadalso, puede verse Miguel Ángel Lama (2009).
} 
Cadalso, que envía a Meléndez un paquete con obras conocidas y desconocidas, como las Noches lúgubres, La Numantina, algunas poesías inéditas como la perdida Canción a la victoria de Melilla, un Compendio de Arte Poética, La Linterna Mágica o la Memoria de los acontecimientos más particulares de mi vida, y que no quiere que se le atribuya póstumamente papel alguno que no haya escrito, demuestra en esta epístola una voluntad terminante de revisión de sus versos y de los Eruditos a la violeta y el Suplemento a los Eruditos a la violeta, al confiar a su amigo estos textos «con las correcciones necesarias». Es decir, lo que realmente hace es corregir sobre páginas impresas -«un juego», dice- de sus obras citadas. Y esto es, en efecto y por fortuna, lo que nos ha llegado a nosotros. Al menos, parte de una prueba documental derivada de aquella carta a Batilo de 1775.

A finales del siglo XIX, el hispanista francés Raymond Foulché-Delbosc (1894) dio a conocer unos papeles inéditos de Cadalso de mucha importancia para completar la historia textual de sus obras. Entre esos papeles manuscritos había poemas y cartas, versiones autógrafas de sus Epitafios para los principales héroes españoles y, según el índice a modo de portada del primero de los cuadernos (figura 1), manuscritos de las Noches lúgubres y las Cartas marruecas, que no figuraban en el lote que publicó Foulché-Delbosc. Las aportaciones crítico-textuales del erudito francés fueron tenidas en cuenta por los estudiosos y editores posteriores de las obras de Cadalso. Principalmente, por Nigel Glendinning (1962) en su libro sobre el escritor gaditano, y también en la edición con Nicole Harrison de su epistolario (Cadalso

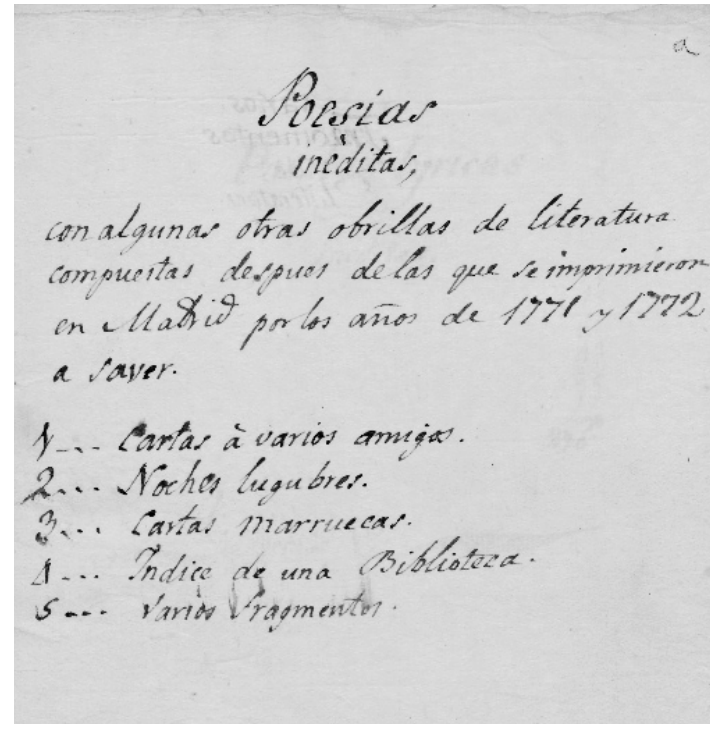

Figura 1 1979); pero igualmente por otros editores modernos como Rogelio Reyes Cano (Cadalso 1993), que incorporó a su edición de la Obra poética la anotación de algunas variantes consignadas por Foulché-Delbosc, a cuyo trabajo inaugural de la Revue Hispanique se ha venido remitiendo en la seguridad del rigor con que se elaboró. Sin embargo, la consulta directa de los documentos que pertenecieron al hispanista permite reparar en un hecho de extraordinaria significación para analizar la consideración que Cadalso tuvo sobre su propia escritura y, en concreto, sobre una de sus obras más originales y, sin embargo, menos editadas modernamente, los Ocios de mi juventud ${ }^{4}$. Para llegar a ello, conviene recorrer el itinerario seguido por los autógrafos de Cadalso dados a conocer en 1894.

Esos papeles que pertenecieron a Raymond Foulché-Delbosc (1864-1929) fueron comprados en 1939 por el librero, editor y traductor catalán establecido en Oxford Joan Gili

\footnotetext{
4 Se encuentra en proceso de publicación mi edición de los Ocios de mi juventud, seguida del resto de la producción poética conocida de Cadalso, que aparecerá en la colección Letras Hispánicas de Ediciones Cátedra en 2013.
} 
i Serra (1907-1998) ${ }^{5}$, que a su vez los vendió a la Biblioteca de la Universidad de Utrecht, en donde otros estudiosos de autores como Meléndez Valdés o Nicolás Fernández de Moratín, con manuscritos también en el mismo legajo, pudieron consultarlos ${ }^{6}$. Así lo hicieron John H. R. Polt y Georges Demerson para su edición de las Obras en verso de Meléndez Valdés (1981: I, 26), que citaron la referencia de la biblioteca de Utrecht para reseñar varios poemas de Batilo, y alguno de letra de Cadalso ${ }^{7}$. Posteriormente, Jesús Pérez Magallón ha tenido en cuenta los manuscritos de Utrecht -un juego distinto al de Cadalso; pero de la misma procedencia- para su edición de las obras de Nicolás Fernández de Moratín (Moratines 2008: 48) y ha aportado alguna información sobre los mismos:

Este manuscrito parece ser el mismo cuyo contenido publicó R. Foulché-Delbosc, Poesías inéditas de D. Nicolás Fernández de Moratín, Madrid, Librería de D. M. Murillo, 1892. Dice Foulché-Delbosc que ese manuscrito proviene de los papeles de José de Cadalso. El manuscrito que se guarda en Utrecht lleva al final una nota, firmada probablemente por Cadalso, donde dice: «Los poemas de don Juan Meléndez están manuscritos originales de su puño en un cuaderno separado. Regalo que él mismo me hizo en Salamanca por el mes de junio 1774». Parece que Foulché-Delbosc ha modificado el orden de los poemas.

Ya en 1966 aparece recogida la colección de manuscritos dieciochescos en el Catálogo (1966: 13) impreso en España de libros españoles y extranjeros sobre España de la Biblioteca Universitaria de Utrecht y su Instituto de Estudios Hispánicos, Portugueses e Hispanoamericanos, en donde se reproduce como ficha con signatura el índice referido anteriormente (figura 1). Pero en 1963 aún se ofrecía en el catálogo de la librería de Joan Gili en Oxford, concretamente en uno de los listados que publicó de los libros y papeles en venta provenientes de la biblioteca de Foulché-Delbosc. En la cuarta entrega (Catalogue 1963: 39), recogió el conjunto de manuscritos cadalsianos, según el librero, «the biggest group of Cadalso's autograph MSs. in existence», al precio de ciento cincuenta y cinco libras, y subrayándose que se trataba de una colección muy apreciada por su propietario anterior, dada su conservación en una caja con cierre y su interés por dar a conocer una parte en sus estudios bibliográficos:

166. PoEsIAS DEL SIGLO XVIII.

A collection consisting of sixteen different sections of published and unpublished MSS of poetry, kept in a box in the shape of a book, with lock.

$£ 155$

This was obviously one of Foulché-Delbosc's favourite collection of manuscripts, to judge by the way in which they are kept and by the fact that some of the contents were published in the Revue Hispanique and elsewhere. They consist mostly of MSs. by Meléndez Valdés, Moratín, Iglesias, and principally Cadalso, as well as many anonymous pieces, such as the Ms. which was partly reproduced in Cuentos y poesías más que picantes.

\footnotetext{
Sobre Joan Gili puede consultarse la semblanza biográfica escrita por Geoffrey Walker (1987: 8-12) para el homenaje publicado por The Anglo-Catalan Society.

6 La referencia actual de este manuscrito es: Poesías del siglo XVIII. Utrecht, Universiteitsbibliotheek Utrecht, Collectie Spaans-Portugees Instituut, ms. 11 (15), 7 cuadernos, 206 páginas. Puede consultarse digitalizado por la Biblioteca de la Universidad de Utrecht en: http://objects.library.uu.nl/reader/resolver. php?obj=002385604\&type=2. Debo la mejor información sobre estos papeles a Philip Deacon, uno de los estudiosos que los han manejado; en su caso, para sus investigaciones sobre Nicolás Fernández de Moratín y sobre la poesía erótica del siglo XVIII. Le agradezco igualmente el dato sobre el Catalogue (1963) de la librería de Joan Gili que se cita más adelante.

7 No puedo precisar en qué fecha consultaron los editores este manuscrito; pero téngase en cuenta que el «Prólogo» a su edición está fechado en junio de 1974.
} 
The principal provenance of the MSs. is from the Salvá and Heredia collections, and from Cadalso, many of whose Mss. are in his hand. There are few known autograph MSs. of Cadalso, apart from Don Sancho García, in the Biblioteca Nacional, and some letters. We can confidently say that this is the biggest group of Cadalso's autograph MSs. in existence.

Otra prueba documental de la presencia de los papeles de Foulché-Delbosc en la librería oxoniense de Gili es la ficha (figura 2) que relaciona el contenido del legajo referido a José de Cadalso y que se conserva en el lote de Utrecht:

Poesias del siglo XVIII.

15)

Cadalso, José, 1741-1782. 7 pieces.

MSS quarto.

a) Poesias inéditas con algunas otras obrillas de literatura compuestas despues de las que se imprimieron en Madrid por los años de 1771 y 1772. Ms. 40 pages. Tied together.

b) Epistola a Batylo y Arcadio. Sobre el rumor de guerra con Portugal y de nueva expedicion contra Argel. Letters to Arcadius [Iglesias, inserto a mano, borde superior derecho], in Latin, Epitaph and Epigram in Latin and Spanish. Carta al Exmo. Sor Marques de Peñafiel Conde Duque de Benavente, y la mitad en lenguaje Español antiguo y despues en el estilo afrancesado que hoy usan algunos de los que ni saven Castellano, ni Frances. Ms quarto 34 pages, 10 of them blank.

c) Epitafios para los monumentos de los principales Heroes Españoles obra Patriota militar dedicada al Principe de Asturias (Nro Señor). In Latin lenguage. 38 pages.

d) Epitaphios para los principales heroes de esta nacion. Partly the same as above with Spanish translation. 40 pages. Epitaph for Fernado [sic]V. (+1512). 4 pages, 2 of them blank.

e) Partly the same as Nrc and d. 30 pages, lose sheets.

f) Epitaph for Garcia Ramirez de Arellano. In Latin. 4 pages, 3 of them blank.

g) [tachado y, al margen, $h$ ] Anacreontica and others. Ms. small quarto, printed, 20 pages.

Published Revue Hispanique 1894, no. 3, November, and obras inéditas de Cadalso, Madrid, 1894.

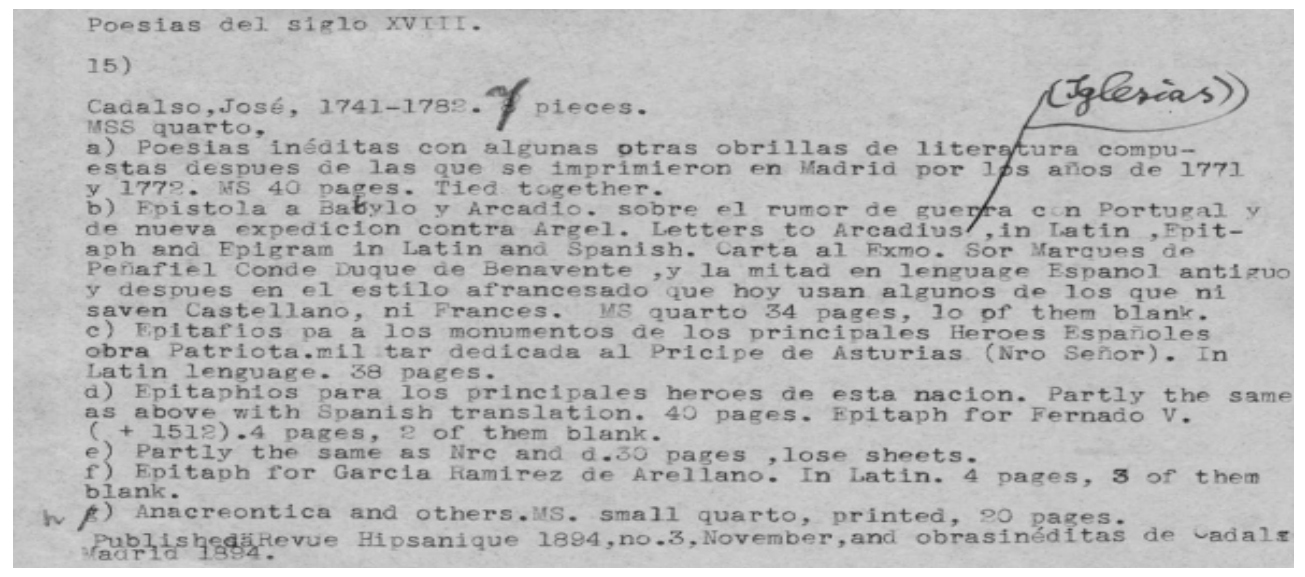

Figura 2 
Definitivamente, el esquema del contenido es el siguiente: 15a. Poesias ineditas, con algunas otras obrillas de literatura compuestas despues de las que se imprimieron en Madrid por los años de 1771 y 1772, á saver 1. Cartas á varios amigos. 2. Noches lugubres. 3. Cartas marruecas. 4. Indice de una Biblioteca. 5. Varios fragmentos. Es el título general en h.1r. Varios fragmentos de Literatura, h.1v.; y Poesías lyricas inéditas, h. 2r (o pág. 3. Son 40 págs., numeradas modernamente a lápiz las impares y la última.) 15b. Epístola a Batilo y Arcadio sobre el rumor de guerra con Portugal y de nueva expedición contra Argel. Letrilla por el mismo estilo que las impresas. Dos cartas en latín a Iglesias de la Casa, publicadas por Foulché-Delbosc (1894: 298-299), y en Cadalso (1979: 105-106 y 110-112), en la última de las cuales está el Epitaphium («Qui jacet hic»), pág. 13. Carta en latín a Meléndez. Cum amico cuidam meo... (y la versión española de Remitiendo a un poeta joven...), pág. 18. Carta al Marqués de Peñafiel. Fragmento de otra a Don Manuel López, en Foulché-Delbosc (1894: 300-304). El cuadernillo consta de 23 págs. 15c. Epitafios. Epitafios para los monumentos de los principales héroes españoles. Obra patriota-militar dedicada al Príncipe de Asturias (Ntro. Señor). 40 págs. 15d. Epitafios para los principales héroes de esta nación. 38 págs. 15e. [Epitafios para los monumentos...] 32 págs. 15f. Epitafio para García Ramírez de Arellano. 4 págs. Texto en 1. 15g. Anacreóntica [«Dime, dime muchacho»] y otros poemas. Son hojas impresas sueltas de Cadalso (1773) con anotaciones autógrafas. 20 págs.

Foulché-Delbosc publicó lo inédito y dio noticia de las variantes que presentaban los textos ya conocidos. Sin embargo, no aludió a las únicas páginas impresas del conjunto, que aparecen en el último lugar y que se corresponden con hojas sueltas extraídas de la primera edición de los Ocios de 1773; pero que presentan anotaciones y marcas manuscritas del autor que constituyen uno de los testimonios más claros de lo que vengo señalando desde el principio de estas líneas: la intervención de Cadalso sobre su obra ya publicada con vistas a una posible reedición de la misma ${ }^{8}$. Recordemos ahora las palabras transcritas arriba del escritor a su amigo Meléndez Valdés incluyéndole también en su envío «un juego de los Eruditos, Suplemento y Poesías con las correcciones necesarias para otra impresión, que intento hacer si vivo, o para cualquiera que se haga si muero», y no será difícil relacionarlas con esas hojas incluidas en el lote.

Como vemos por la ficha elaborada por The Dolphin Book $C^{\circ}$ (Joan Gili), se constata la existencia de esa veintena de páginas; pero quien verdaderamente llamó la atención sobre la particularidad de ese material fue el hispanista británico Nigel Glendinning, que lo pudo ver, y a ello aludió en un temprano artículo sobre el sobrenombre poético de Ortelio que aparece en la poesía de Cadalso (Glendinning 1958: 6, n. 9), en donde leemos:

Los papeles de Cadalso que pertenecían a M. Foulché-Delbosc pasaron después de su muerte al señor J. Gili del Dolphin Book Company, Oxford, que actualmente los tiene. Muy amablemente el señor Gili me ha dejado consultar con entera libertad estos interesantes documentos. Los he aprovechado aquí.

Más tarde, en su libro sobre la vida y la obra del autor de las Cartas marruecas, Nigel Glendinning (1962: 38 y 181, n. 22) hablará de las revisiones que Cadalso «estaba haciendo a sus poesías impresas poco antes de su muerte» y volverá a aludir a su lectura de los papeles provenientes de la biblioteca de Foulché-Delbosc:

Se encuentran algunas páginas de la edición hecha por Sancha de los Ocios de mi juventud (Madrid, 1773), corregidas por el autor, entre los papeles de Cadalso que compró Foulché-Delbosc

\footnotetext{
8 Identifico con la abreviatura Utrecht con su número y su letra (15g) el cuadernillo que contiene las páginas impresas de los Ocios a que me refiero en estas líneas.
} 
a fines del siglo pasado, y que pertenecen actualmente a mi buen amigo don Joan Gili, de la Dolphin Book Company, Oxford. El señor Gili muy amablemente me permitió ver estos papeles. Cadalso tachó completamente la Anacreóntica «Dime, dime, muchacho» y, en un principio, también «Mi dulcísimo amigo»; quería eliminar los dos últimos versos de «Los que no saben, Baco». No sabemos por qué no se incorporaron estas y otras revisiones en la edición de los Ocios hecha por Hernández Pacheco, en Madrid, en 1781. Quizá, por estar en Gibraltar, Cadalso no podía cuidar de su impresión?.

Solo la escasa atención que ha provocado esta parte de la producción de Cadalso, oscurecida por la nombradía de las Noches lúgubres y de las Cartas marruecas, y, sin embargo, de infrecuente originalidad; solo su escasísima difusión moderna y las pocas iniciativas por fijar definitivamente los textos poéticos de este autor, puede explicar que un hecho tan notorio desde el punto de vista de la transmisión textual de una obra moderna haya pasado tan inadvertido, y haya quedado relegado a alusiones incidentales o a alguna nota meramente informativa ${ }^{10}$. Pues lo que resulta de las indicaciones manuscritas de Cadalso sobre las páginas impresas de sus Ocios tiene, en primer lugar, la trascendencia de que altera la composición del libro que casi invariablemente ha llegado hasta nosotros desde hace más de doscientos años; un libro en el que Cadalso demostró un afán constructivo más que considerable. Por otro lado, las anotaciones autógrafas eliminan o enmiendan lecturas de los poemas -pocos, es verdad- que deberían incorporarse como texto principal o autorizado a cualquier edición de los mismos. Resumiré estas correcciones de Cadalso sobre sus poemas.

\begin{tabular}{|c|c|}
\hline 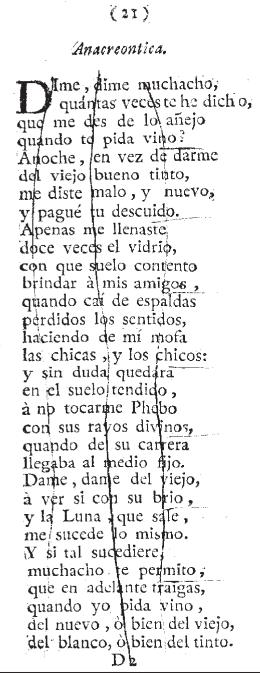 & 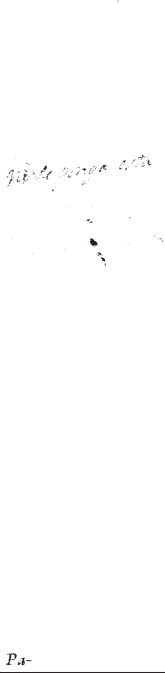 \\
\hline
\end{tabular}

Figura 3
La consecuencia más notoria en este caso de la actuación del autor sobre su obra es la eliminación, como ya he dicho, de uno de los poemas que desde 1773 hasta hoy se ha venido editando en el mismo lugar -décimo segundo- de los Ocios: la anacreóntica «Dime, dime, muchacho». Se publicó (Cadalso 1773: 21) entre los poemas $A$ un héroe, advirtiendo que aprecie a los poetas... y Pasatiempos, y sobre esa página impresa de esa edición Cadalso tachó con tres líneas verticales el poema, y anotó al margen: «no se ponga esta» (Figura 3). Quizá el autor creyó, como señaló Glendinning (1962: 38), que se trataba de una anacreóntica endeble y demasiado convencional, y consideró conveniente eliminarla. Endeble quizá; pero solo convencional por la presencia del vino para adormir las penas, pues narra cómo el personaje bebió la noche anterior doce copas de vino malo y nuevo -contra la costumbre de beber

\footnotetext{
9 Años después, Glendinning y Harrison (1979: 155), en la anotación a la carta ya mencionada de Cadalso a Meléndez Valdés: «Algunas páginas de los Ocios de mi juventud (1773) con correcciones hechas por Cadalso se encontraban entre los manuscritos de Foulché-Delbosc. En el margen de la Anacreóntica «Dime, dime, muchacho», por ejemplo, escribió «No se ponga ésta». Quería omitir también «Mi dulcísimo amigo», y tachó versos de otros poemas».

10 Rogelio Reyes Cano (1992: 37, 40 y 137) mencionó en su edición, a partir de Glendinning (1962), estas apuntaciones de Cadalso.
} 
«del viejo bueno tinto»-, cómo cayó de espaldas, «perdidos los sentidos», y no despertó hasta el mediodía siguiente. Y pide al muchacho al que se dirige que le dé en ese momento del vino añejo para comprobar si le sucede lo mismo hasta la noche; y que si fuese así, ya le daría igual que le trajese vino viejo o nuevo, vino blanco o tinto; casi como una proposición de pasar el día y la noche ausente y evadido. Quizá, pues, Cadalso pensase en que, sobre la convención, fue extremoso.

El mismo destino pudo tener A un amigo sobre el consuelo que da la poesía (Cadalso 1773: 22-24), otra anacreóntica que acompañaba a la anterior en el juego de hojas de los Ocios. « $\mathrm{Ni}$ esta», escribió y tachó Cadalso, que, decidido a conservarla en una futura reedición de sus versos, modificó el antetítulo genérico de «Anacreóntica» por el de «Idilio anacreóntico». Este cambio introduce una serie de anotaciones que presentan los manuscritos referidas a la caracterización genérica de los poemas, y que afecta, además de este idilio; a El poder del oro en el mundo. Diálogo entre Cupido y el Poeta (Cadalso 1773: 31), al que añade debajo del título: «Epigrama»; a A las bodas de Lesbia (Cadalso 1773: 39), que en todas las ediciones lleva la indicación de «Anacreóntica» y que el poeta tachó en los papeles de Utrecht; a la «Anacreóntica» que comienza «Los que no saben Baco» (Cadalso 1773: 85-87); y a la siguiente, que comienza «Vivamos, dulce amigo» (Cadalso 1773: 87-90), que Cadalso renombra como «Idilio anacreóntico», como hizo con A un amigo sobre el consuelo que da la poesía. Se confirma, pues, en la conciencia poética del autor un prurito por precisar la filiación genérica de sus textos y matizar en ellos la diferencia entre una oda anacreóntica y un idilio anacreóntico, que sería una especie de variante de la primera, relacionable, como hizo Philip Deacon (1995: 213), con subgéneros españoles como las barquillas de Lope de Vega, y que contenía cierto componente narrativo de una experiencia idílica amorosa. En palabras de Deacon (1995: 214), en «algunos casos un crítico purista negaría el título genérico a ciertos poemas por mostrar divergencias demasiado grandes de uno $\mathrm{u}$ otro modelo dentro del sistema. No obstante, el poeta creador no vacilaría en experimentar si esperaba alcanzar un efecto artístico más logrado». Sin duda, Cadalso ejerció de poeta y de crítico de sí mismo.

El resto de variantes reseñables afecta ya a versos y palabras de los poemas citados y de otros como Carta de Florinda a su padre el Conde D. Julián después de su desgracia (Cadalso 1773: 25-31), del que se eliminan seis versos («Florinda, ya se acaba / de mi persecución el necio empeño; / aun mi alma se alaba / de humillarse a la fuerza de tu ceño; / vive felice sin temor ni susto, / ya no aspiro a más gusto que tu gusto». vv. 121-126) o el Cuento «En el oscuro bolsillo» (Cadalso 1773: 41-42) que cambia «óigalo el sabio y discreto» (v. 56) por «oigalo el sabio y el necio», para evitar una repetición con el verso décimo del poema y aportar un matiz más totalizador; y cambia también «porque se oyeran enredos» (v. 58) por "porque se oyeran secretos», al tiempo que elimina dos versos que han venido apareciendo siempre en todas las ediciones de la poesía cadalsiana: «culpas, delitos y fraudes, / osadías y portentos». Por supresión opera igualmente Cadalso sobre el poema $A$ un amigo sobre el consuelo que da la poesía, del que propone eliminar los versos 38-39 de la primera edición («sino aquel desahogo / que en la musa encontramos») y los dos finales («y todo sin más armas / que la pluma en la mano.»); y otros textos enmendados serán las anacreónticas «Unos sabios gritaban» (Cadalso 1773: 40-41) y la ya mencionada «Los que no saben Baco», que demuestran la relectura a la que sometió el autor a su obra.

En conclusión, si el tratamiento textual del corpus poético publicado en vida de su autor, es decir, de los Ocios -cincuenta y seis poemas sin versiones manuscritas-, es relativamente cómodo, la existencia de esos testimonios de corrección del autor redoblan la importancia 
que para éste tuvo su primer y único libro de versos. Por ello, mi propuesta de edición es la de dar nuevamente el volumen titulado Ocios de mi juventud, privilegiándolo como pieza con estructura, concebida como libro de poemas; más el añadido -Y otros poemas- de los textos conocidos póstumamente, algunos de los cuales nos han llegado en copias manuscritas autógrafas y de otras manos. Sobre esta base, me parece incontestable que la difusión moderna de la poesía de Cadalso ha de tomar como texto principal y autorizado el que se deriva de las instrucciones dadas por el escritor gaditano en los papeles de Utrecht, y, por consiguiente, no solo reflejar las variantes con respecto a la edición príncipe de 1773, sino, en el caso de la anacreóntica «Dime, dime muchacho», llevarla al apéndice de «Y otros poemas» y no poner lo que el autor no quiso que se pusiese. Con una edición sin ese poema en el cuerpo central del libro, y con las enmiendas y supresiones mencionadas, nos encontraríamos ante la primera que se publica desde el tiempo de Cadalso que respeta la voluntad del autor expresada génericamente a su amigo Meléndez Valdés y materializada sobre el papel en la veintena de páginas que hemos podido conservar gracias a filólogos como Foulché-Delbosc, libreros como Joan Gili e investigadores como Nigel Glendinning.

\section{Bibliografía}

Cadalso, José de (1771), Don Sancho García, Conde de Castilla. Por Juan del Valle, Madrid, Joaquín Ibarra.

CADALSO, José de (1772a), Los Eruditos a la violeta, o Curso completo de todas las ciencias, dividido en siete lecciones para los siete días de la semana. Compuesto por Don Joseph Vazquez, quien lo publica en obsequio de los que pretenden saber mucho, estudiando poco, Madrid: Antonio de Sancha.

CADALSo, José de (1772b), Suplemento al papel intitulado Los Eruditos a la violeta, compuesto por Don Joseph Vazquez, Madrid: Antonio de Sancha.

Cadalso, José de (1773), Ocios de mi juventud, o Poesías líricas de D. Josef Vázquez, Madrid: Imprenta de D. Antonio de Sancha.

Cadalso, José de (1781), Ocios de mi juventud, o Poesías líricas de D. Josef Vázquez en continuación de los Eruditos a la violeta, Madrid: Imprenta de Isidoro de Hernández Pacheco.

Cadalso, José de (1782), Ocios de mi juventud, o Poesías líricas de D. Josef Vázquez en continuación de los Eruditos a la violeta, Barcelona: Imprenta de Eulalia Piferrer Viuda.

CAdalso, José de (1792), Epístola dedicada a Hortelio, o Poesías inéditas del Coronel Don Josef Cadalso, Caballero del hábito de Santiago, Comandante del Regimiento de Caballería de Borbón, que murió en Gibraltar en 1782, Madrid: Isidoro de Hernández Pacheco.

CADAlso, José de (1803), Obras de Don Joseph Cadalso, Coronel y Comandante del Esquadron del Regimiento de Borbón, y Caballero del hábito de Santiago, Madrid: Por Don Mateo Repullés, volumen II, 5-224.

CADAlso, José de (1961), Noches lúgubres. Edición, prólogo y notas de Nigel Glendinning, Madrid: Espasa-Calpe.

CAdalso, José de (1979), Escritos autobiográficos y epistolario. Prólogo, edición y notas de Nigel Glendinning y Nicole Harrison, London: Tamesis Books Limited.

CADAlso, José de (1987), Autobiografía. Noches lúgubres. Edición de Manuel Camarero, Madrid: Editorial Castalia.

CADAlso, José de (1993), Obra poética. Edición, introducción y notas de Rogelio Reyes Cano, Cádiz: Servicio de Publicaciones de la Universidad de Cádiz. 
Cadalso, José de (2002), José de Cadalso. Biblioteca de autor en la Biblioteca Virtual Miguel de Cervantes. http://www.cervantesvirtual.com/bib_autor/cadalso

CAtálogo (1966) España e Hispanoamérica: catálogo de libros españoles y publicaciones extranjeras sobre Españae Hispanoamérica. Suplemento IX. Bibliotheekder Rijksuniversiteit te Utrecht in samenwerking met de Stichting «Het Spaans, Portugees en IberoAmerikaans Instituut». Utrecht: Biblioteca Universitaria de Utrecht en colaboración con el Instituto de Estudios Hispánicos, Portugueses e Hispanoamericanos de la Universidad de Utrecht, Valencia: Artes Gráf. Soler.

Catalogue (1963) Catalogue $n^{\circ}$ XLII. The Foulché-Delbosc Library Part IV. Spanish Manuscripts, Oxford: The Dolphin Book Co Ltd.

DeAcon, Philip (1995), «La maleabilidad del neoclasicismo: aproximaciones a la poesía española del siglo XVIII», in: Estudios dieciochistas en homenaje al profesor José Miguel Caso González, Oviedo: Instituto Feijoo de Estudios del Siglo XVIII, volumen I, 207-218.

Foulché-Delbosc, R., (1894), «Obras inéditas de Cadalso», Revue Hispanique I, 258335. También: Obras inéditas de D. José Cadalso. Editadas por R. Foulché-Delbosc, Madrid: Librería Murillo, 1894.

GLENDINNING, Nigel (1958), "Ortelio en la poesía y en la vida de Cadalso. Una nueva teoría sobre su identidad y datos sobre la amistad de Casimiro Gómez Ortega y Cadalso", Revista de Literatura XIV, núms. 27-28, 3-23.

GLENDINNING, Nigel (1962), Vida y obra de Cadalso, Madrid: Gredos («Biblioteca Románica Hispánica», Estudios y ensayos, 55).

LAMA, Miguel Ángel (2009), «La fortuna póstuma de la poesía de José Cadalso (entre 1786 y 1807)», in: LoRENZo Álvarez, Elena de (coord.), La época de Carlos IV (17881808). Actas del IV Congreso Internacional de la Sociedad Española de Estudios del Siglo XVIII, Oviedo: Instituto Feijoo de Estudios del Siglo XVIII, Sociedad Española de Estudios del Siglo XVIII, Sociedad Estatal de Conmemoraciones Culturales, 665676.

Martínez Mata, Emilio, «Prólogo» a su edición de Cadalso, José de, Cartas marruecas. Noches lúgubres. Edición de Emilio Martínez Mata. Estudio preliminar de Nigel Glendinning, Barcelona: Editorial Crítica, 2000. XXXI-LXXXIX.

Meléndez Valdés, Juan (1981), Obras en verso. Ed. crítica, prólogo y notas de Juan H. R. Polt y Jorge Demerson, Oviedo: Centro de Estudios del Siglo XVIII, 2 vols.

Moratines, Los (2008), Obras completas I. Obras de Nicolás F. de Moratín. Diarios. Epistolario de Leandro. Ed., introducción y notas de Jesús Pérez Magallón, Madrid: Ediciones Cátedra (Bibliotheca Avrea).

WALKER, Geoffrey J. (1987), «Joan Gili», en Homage to Joan Gili on his Eightieth Birthday. Forty Modern Catalan Poems Chosen and Introduced by Arthur Terry with English Prose Translations by Members of The Anglo-Catalan Society, Sheffield, The Anglo-Catalan Society, 8-12.

Miguel Ángel Lama Hernández

Dpt. Filología Hispánica y Lingüística General Facultad de Filosofía y Letras Universidad de Extremadura Avda. de la Universidad s/n 10071 Cáceres

España

malama@unex.es 